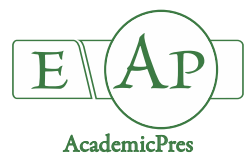

\title{
Quality Performances of Sweet Pepper under Farming Management
}

\author{
Gianluca CARUSO ${ }^{1}$, Vasile V. STOLERU ${ }^{2 *}$, Neculai C. MUNTEANU², \\ Vincenzo Michele SELLITTO ${ }^{3}$, Gabriel Ciprian TELIBAN ${ }^{2}$, \\ Marian BURDUCEA ${ }^{4}$, Ioan TENU², Giuseppe MORANO ${ }^{1}$, \\ Monica BUTNARIU ${ }^{5}$
}

\author{
${ }^{1}$ University of Naples "Federico II", Department of Agricultural Sciences, via Università 100, 80055 Portici, NA, \\ Italy; gcaruso@unina.it; giu.morano90@gmail.com \\ ${ }^{2}$ University of Agriculture Sciences and Veterinary Medicine, Department of Horticulture, 3 M. Sadoveanu, 700490, Iasi, \\ Romania; vstoleru@uaiasi.ro(*correspondingauthor);nmunte@uaiasi.ro;gabrielteliban@uaiasi.ro; itenu@uaiasi.ro \\ ${ }^{3}$ MsBiotech SPA, Department of Microbiology, 00198, Via Zara 23, Roma, Italy; michele.sellitto@msbiotechspa.com \\ ${ }^{4}$ Al. Ioan Cuza University, 11 Carol Street, 700506, Iasi, Romania; marian.burducea@yahoo.com \\ ${ }^{5}$ Banat's University of Agricultural Sciences and Veterinary Medicine "King Michael I of Romania" from Timisoara, 300645, \\ Calea Aradului 119, Timis, Romania; monicabutnariu@yahoo.com
}

\begin{abstract}
Conventional management of sweet pepper is based on farming practices characterized by the use of chemicals with harmful environmental impact. In order to investigate innovative production, research was carried out in order to assess the effects of two pepper cultivars ('Brillant' and 'Yolo Wonder') in combination with four farming systems (Conventional control-C; Conventional with microorganism-enriched fertilization-CMF; Organic control-O; Organic with microorganismenriched fertilization-OMF) on plant physiological parameters, yield and fruit quality. Conventionally grown plants showed higher values of assimilatory pigments and of photosynthetic rate compared to the Organically ones. The CMF resulted in the highest early and total yield, followed by the OMF, due to higher fruit number. Higher values of carotenoids, ascorbic acid and $\alpha$-tocopherol were recorded in 'Yolo Wonder' red fruits compared to 'Brillant' yellow berries. The highest total polyphenols concentration was recorded under the CMF, whereas OMF resulted in the highest flavonoids concentration and antioxidant activity.
\end{abstract}

Keywords: biochemical compounds; Capsicum annuum L.; plant growth; yield

\section{Introduction}

Sweet pepper (Capsicum annuum L. ssp. annuum) is a thermophile vegetable species, which worldwide produces over 26 million tons of fruits (FAOSTAT, 2014). Pepper fruits are an important source of antioxidants, such as ascorbic acid, carotenoids, tocopherols (Sreeramulu and Raghunath, 2010), phenolic compounds, particularly flavonoids (Chen and Kang, 2013); in addition, their flavour and nutritional value are affected by organic acids and sugars (Luning et al., 1994). Notably, polyphenols and flavonoids have been recently in high regard for evaluating pepper fruit value (Deepa et al., 2007), as they protect the human organism cells against the oxidation caused by free radicals (Costa et al., 2013). Indeed, they have shown beneficial bioactivities to human health, such as reducing risk of cancer, heart diseases, diabetes (Pend et al., 2015; Shahidi and Ambigaipalan, 2015; Serpeloni et al., 2015) and, notably, their antioxidant activity depends on their hydroxyl groups number and arrangement (Zhuang et al., 2012; Grajeda-Iglesias et al., 2016). Yield and fruit quality performances of sweet pepper are reportedly affected by genotype (Thanopoulos et al., 2013; Tundis et al., 2013; Loizzo et al., 2015) and farming system (Lopez et al., 2014). Notably, organic farming is aimed to meet requirements concerning yield stability and food security, which are the consequence of efficient plant development, in turn resulting in optimal fruit number and weight as well as high berry quality (Conti et al., 2014). Moreover, as an eco- 
compatible system, organic horticulture is more susceptible to unbalances, owing to the less intensive management (Maynard, 1994) and, therefore, fertilization plays a key role (Stoleru et al., 2014), though its influence on physiological processes is reportedly controversial (Fu et al., 2010). In the view of non-polluting strategies, research on interactions between fertilization and beneficial microorganisms on vegetable production and quality as well as on biotic and abiotic stress prevention have been carried out by several authors (Del Amor et al., 2008; Stefan et al., 2013). In this respect, arbuscular mycorrhizal fungi (AMF) play a significant role in plant performance and nutrition, due to their ability to improve plant mineral uptake (Smith and Read, 2008). AMF are obligate symbionts, as they can only be grown in the presence of host plants (Owen et al., 2015), and they are widely used in horticulture, particularly Rhizophagus intraradices and Funneliformis mosseae (Krüger et al., 2012). Notably, positive effects of Glomus spp. on vegetable crops were recorded both in open field and in greenhouse (Nadeem et al., 2014; Rouphael et al., 2015). The aim of the present research was assessing the effects of organic or conventional system on sweet pepper cultivars, in terms of plant physiology and growth, as well as of yield and fruit quality, the latter mainly focused on antioxidant content and activity.

\section{Materials and Methods}

\section{Plant material and growth conditions}

Research was carried out on sweet pepper crop (Capsicum annuum L. ssp. annuum) under polytunnels during 2015 and 2016, at the experimental station of University of Agricultural Sciences and Veterinary Medicine (UASVM) in Iasi $\left(47^{\circ} 11^{\prime} 76^{\prime \prime} \mathrm{N}, 27^{\circ} 33^{\prime} 71^{\prime \prime} \mathrm{E}, 150\right.$ $\mathrm{m}$ a.s.l.). The monthly mean temperature attained the highest value $\left(21.3{ }^{\circ} \mathrm{C}\right)$ in July and the lowest in October $\left(11.6^{\circ} \mathrm{C}\right)$. The soil characteristics were as follows: $62 \%$ sand, 6\% silt, $32 \%$ clay, $\mathrm{pH} 7.2$, EC $478 \mu \mathrm{S} \cdot \mathrm{cm}^{-1}, 28.6 \mathrm{~g} \cdot \mathrm{kg}^{-1}$ organic matter, $2.8 \mathrm{~g} \cdot \mathrm{kg}^{-1} \mathrm{~N}, 32 \mathrm{mg} \cdot \mathrm{kg}^{-1} \mathrm{P}, 224 \mathrm{mg} \cdot \mathrm{kg}^{-1} \mathrm{~K}, 4.1$ g. $\mathrm{kg}^{-1} \mathrm{CaCO}_{3}$. The experimental protocol was based on the factorial combination between two cultivars ('Brillant', 'Yolo Wonder') and four farming systems (Conventional control, C; Conventional with microorganism-enriched fertilization, CMF; Organic control, O; Organic with microorganism-enriched fertilization, OMF); a split plot design was used with three replicates and the elementary plot had a $10.1 \mathrm{~m}^{2}$ surface area $(3.6 \times 2.8 \mathrm{~m})$. The four farming systems are described in details as follows:

a. $\mathrm{C}$ representing a conventional crop management based on the traditional chemical fertilization, achieved applying solid chemical fertilizers, whose overall amount was based on pepper nutrient requirements and split in three applications: $300 \mathrm{~kg} \cdot \mathrm{ha}^{-1}$ of Cristaland ${ }^{\oplus}$ (NPK 20-2020) just before planting; $500 \mathrm{~kg} \cdot \mathrm{ha}^{-1}$ of Cristaland ${ }^{\oplus}$ (NP 15$50+\mathrm{MgO} 2)$ at the beginning of floral bud phase; 720 kg.ha ${ }^{-1}$ of Cristaland ${ }^{\bullet}$ (NPK 9-18-27+ MgO).

b. CMF - consisting of a conventional crop management with the fertilization based on fertigations with microorganism-enriched chemical fertilizers, preceded by a starting fertilizer application; it was aimed at supplying a total fertilizers amount equivalent to $55 \%$ of the one associated to the traditional fertilization above described, taking into account the higher nutrient use efficiency achieved by fertigation. CMF was performed as follows: application of $100 \mathrm{~kg} \cdot \mathrm{ha}^{-1}$ of Cristaland ${ }^{\circledR}$ (NPK 20-20-20) just before planting; fertigations practiced during crop cycle. The fertigations were carried out using the following fertilizers: $70 \mathrm{~kg} \cdot \mathrm{ha}^{-1}$ of Nutrispore ${ }^{\oplus}$ (NPK $30-10-10$ plus $\mathrm{Mg}, \mathrm{B}, \mathrm{Fe}, \mathrm{Mn}, \mathrm{Zn}$ and microorganisms) during the vegetative phase; $230 \mathrm{~kg} \cdot \mathrm{ha}^{-1}$ of Nutrispore ${ }^{\circledast}$ (NPK 15-10-30 plus $\mathrm{Mg}, \mathrm{B}, \mathrm{Fe}, \mathrm{Mn}, \mathrm{Zn}$, and microorganisms) starting at floral bud phase; $290 \mathrm{~kg} \cdot \mathrm{ha}^{-1}$ of Nutrispore ${ }^{\oplus}$ (NPK 12-48-8 plus $\mathrm{Mg} \mathrm{B}, \mathrm{Fe}, \mathrm{Mn}, \mathrm{Zn}$ and microorganisms), starting at first fruit setting.

c. O- representing an organic farming system based on organic fertilization, amounted to $50 \%$ of the overall fertilizers rate associated to the traditional chemical fertilization, taking into account the higher nutrient use efficiency achieved by organic fertilization, practiced through the application of $15 \mathrm{q} \cdot \mathrm{ha}^{-1}$ organic fertilizer (NPK 6-5-13) before planting.

d. OMF - was an organic crop management consisting of a beneficial microorganisms application plus an organic fertilization: the former was performed by supplying 60 $\mathrm{kg} \cdot \mathrm{ha}^{-1}$ of Micoseed $\mathrm{MB}^{\oplus}$, two days before planting; the organic fertilization amounted to $50 \%$ of the overall fertilizers rate associated to the traditional chemical fertilization, taking into account the higher nutrient use efficiency achieved by organic fertilization, and it was practiced as follows: $15 \mathrm{q} \cdot \mathrm{ha}^{-1}$ organic fertilizer (NPK 6-513) before planting; four supplies of Nutryaction ${ }^{\circ}(1 \%$ organic N), each at $5 \mathrm{~L} \cdot h a^{-1}$, equally provided during the vegetative and fruiting stages, aimed at stimulating the microorganisms action.

The microorganism applications were achieved by formulates containing arbuscular mycorrhizal fungi (AMF) spores, based on Glomus spp., complexed with Beauveria sp., Metarhizium sp. and Trichoderma sp. In all treatments, drip irrigation or fertigation was activated when the soil available water capacity decreased to $80 \%$.

Fifty-five days old seedlings were transplanted on 16 April and spaced $35 \mathrm{~cm}$ along the rows which were $90 \mathrm{~cm}$ apart (3.2 plants $\left.\cdot \mathrm{m}^{-2}\right)$. Harvests were practiced from 20 July to 19 October, when the fruits reached the full ripeness stage. Ripe, undamaged and regularly shaped fruits heavier than $80 \mathrm{~g}$ were classified as "marketable".

\section{Fruit sample preparation}

At harvest, a $2 \mathrm{~kg}$ sample of fully ripe fruits was taken from each experimental plot and transferred to laboratory for analyses. After removing seeds and stalk from each fruit, the flesh was chopped in 5-10 mm pieces which were water evaporated. Then, a $400 \mathrm{~g}$ aliquot from each sample was dehydrated in an oven, at a temperature of $38^{\circ} \mathrm{C}$ for 14 days until constant weight; next, the samples were kept at $24^{\circ} \mathrm{C}$ in dry atmosphere (Butnariu, 2014). Ten grams of dried fruits were treated with $100 \mathrm{~mL}$ extracting solvent, a mixture of ethanol (45\%) and water $(65 \%)$ and the extraction procedure lasted seven days under darkness and at $25^{\circ} \mathrm{C}$ air temperature. 
460

\section{Dry residue}

Dry residue was assessed after dehydration of the fresh samples in an oven at $70{ }^{\circ} \mathrm{C}$ under a vacuum until they reached constant weight.

\section{Soluble solids content}

The soluble solids content or SSC (in ${ }^{\circ}$ Brix) was measured at $20{ }^{\circ} \mathrm{C}$ on the supernatant obtained from raw homogenate centrifugation, using a Bellingham and Stanley digital refractometer, model RFM 81 (Tunbridge Wells, $\mathrm{UK})$.

\section{HPLC analysis}

Organic acids and carotenoids were determined by high performance liquid chromatography (HPLC) as previously described (Conti et al., 2014). Tocopherols were determined by high performance liquid chromatography (HPLC) as described by Osuna-Garcia et al. (1998).

\section{Totalpolyphenols}

The polyphenols were analyzed by UV-Vis spectrophotometry, using the Folin-Ciocalteu method. The calibration curve was performed using gallic acid as a standard $\left(100-1400 \mu \mathrm{g} \cdot \mathrm{mL}^{-1}\right)$. Antioxidant activity is expressed in mg equivalent gallic acid. $100 \mathrm{~g}^{-1}$ sample. The reduction test of Folin-Ciocalteu reagent was done by a method for quantifying phenolic compounds in complex products with antioxidant activity.

\section{Total flavonoids}

The flavonoid content was assessed using the spectrophotometric method for the quantitative determination, based on its reaction with aluminum chloride. The calibration curve was made using quercetin 3rhamnoglucoside as a routine standard $\left(50-500 \mu \mathrm{g} \cdot \mathrm{mL}^{-1}\right)$. The samples were prepared by mixing them $(0.5 \mathrm{~mL}$ dilution) with $25 \%$ alcohol $(0.4 \mathrm{~mL})$ and $10 \%$ sodium acetate $(0.5 \mathrm{~mL})$; then, the samples were stored in darkness at room temperature for 30 minutes. The absorbance was determined at wave length of $430 \mathrm{~nm}$.

\section{Antioxidant assays}

The extracts used for the antioxidant activity were obtained following the procedure described by MínguezMosquera and Hornero-Méndez (1993). Twenty-five mg samples were extracted with $5 \mathrm{~mL}$ of acetone $(60 \%)$ and water (40\%) mixture, using an ultrasonic liquid processor Vibra Cell VC365 set at 90 intensity $(0-100$ scale, $20 \mathrm{kHz})$ for 8 minutes. Samples were sonicate in an ice-water bath in order to avoid excessive heating and degradation of carotenoids. After sonication, samples were centrifuged at $16,500 \mathrm{rpm}$ for 5 minutes and the supernatant removed. The process was repeated twice performing the extraction with a vortex during $15 \mathrm{~s}$ and a subsequent centrifugation. A final extraction with $10 \mathrm{~mL}$ of an acetone-water mixture was achieved, being the four extracts combined, filled up to $25 \mathrm{~mL}$ and stored until analysis.

The antioxidant capacity was assessed through two methods: $\mathrm{ABTS}^{+}$and DPPH assay (Larrosa et al., 2015). The $\mathrm{ABTS}^{+}$assay is based on antioxidant capacity determination by using radical cation 2,2'-Azino-bis (3- ethylbenzothiazoline-6-sulfonic acid) known as ABTS $^{+}$. The DPPH is based on the inhibition of the free radicals by the 1,1-Diphenil-2 pecryl-hydroxyil or DPPH as a monitor of chemical reaction involving radicals.

\section{$A B T S^{+}$assay}

The pepper fruit antioxidant capacity was assessed in terms of radical scavenging activity, following the procedure described by Re et al. (1999) with slight modifications (Butnariu, 2014). In this respect, $\mathrm{ABTS}^{+}$was produced upon reaction of $7 \mathrm{mM}$ ABTS stock solution with $2.45 \mathrm{mmol} \cdot \mathrm{L}^{-1}$ potassium persulphate and allowing the mixture to stand in the dark at room temperature for 12 to 16 hours before use. The $\mathrm{ABTS}^{+}$solution (stable for 2 days) was diluted with $5 \mathrm{mmol} \cdot \mathrm{L}^{-1}$ phosphate buffered saline $(\mathrm{pH}$ 7.4 ) to an absorbance of $0.70 \pm 0.02$ at $730 \mathrm{~nm}$. After adding $100 \mu \mathrm{L}$ extract or trolox standard to $1 \mathrm{~mL}$ of diluted $\mathrm{ABTS}^{+}$solution, absorbance was read after 20 minutes using a Lambda 25 spectrophotometer. Calibration was performed, as previously described. Results were expressed as $\mu \mathrm{mol}$ equivalents of trolox per $\mathrm{g}$ of sample.

\section{DPPH assay}

The pepper fruit antiradical activity was assessed according to the procedure reported by Grajea-Iglesias et al. (2016). A $500 \mu \mathrm{L}$ aliquot of the extract or trolox standard was added to $1 \mathrm{~mL}$ of DPPH. methanol solution (74 $\left.\mathrm{mg} \cdot \mathrm{L}^{-1}\right)$. A daily-prepared solution of DPPH. showed a final absorption at $520 \mathrm{~nm}$ of $1.8 \mathrm{AU}$. The mixture was shaken and allowed to stand for 1 hour at room temperature and, then, the absorption was measured at $520 \mathrm{~nm}$ in a Lambda 25 spectrophotometer. The antiradical activity of sample is inversely correlated with its purple colour intensity. Aqueous solutions of trolox at various concentrations were used for calibration $\left(0.15-1.15 \mathrm{mmol} \cdot \mathrm{L}^{-1}\right)$. The results were expressed as $\mu \mathrm{mol}$ equivalents of trolox (an analog of vitamin E) per $\mathrm{g}$ of sample (TEAC-Trolox Equivalent Antioxidant Capacity).

\section{Statistical analysis}

Data were statistically processed by two-way analysis of variance, using SPSS software version 21 , and only the results relevant to the main effects of the two experimental factors and to their significant interactions were reported and discussed; mean separations were performed through the Duncan multiple range test, with reference at 0.05 probability level.

\section{Results and Discussion}

\section{Plant growth and fruit production}

From the analysis of variance relevant to plant growth and yield data, significant effects of the year of research, of the cultivar and of the farming system on leaf area index and on yield parameters were recorded (Table 1). Notably, in 2016 pepper plants showed a higher leaf expansion which led to heavier fruits and, accordingly, to higher early and total yield, compared to the first research year.

No significant differences were detected between the two cultivars examined, both in terms of plant growth and yield; in fact, there was a balance between the higher berry 
number showed by cultivar 'Brillant' and the heavier fruits of cultivar 'Yolo Wonder'.

As for farming system (Table 1), CMF resulted in the highest early and total yield, followed by OMF showing a $21.5 \%$ and $16.0 \%$ decrease in early and total yield respectively; $\mathrm{O}$ ranked last with a $42.1 \%$ and $35.0 \%$ decrease in early and total yield respectively, compared to CMF. Notably, the two most effective treatments did not differ from each other with regard to plant growth and mean fruit weight, but CMF led to higher berries number than OMF. Contrastingly, Lopez et al. (2013) reported lower mean fruit weight of organically grown pepper compared to the conventional management. However, in our research CMF encouraged plant growth, fruiting precocity and yield, both by making the nutrients readily available for the plants through fertigation and by supplying microorganisms which enriched the soil microbial community. Moreover, microorganisms can exert beneficial effects to plants, by improving the absorption of soil nutrients from insoluble or immobilized forms (Ortas et al., 2011). The latter function is particularly needed when the air temperature values are under the threshold allowing an efficient plant nutrient absorption (Shaked et al., 2004) or over this limit (Khah and Passam, 1992), thus causing fruit size and crop yield drop. In our research, the improvement of plant nutrient absorption efficiency encouraged by beneficial microorganisms occurred under OMF, based on organic fertilization with microorganisms' application, which showed higher yield performances compared to the same organic fertilization without microorganisms application $(\mathrm{O})$. OMF presumably enhanced the activity and biomass of soil microbial community, which is positively related to organic matter (Graham and Haynes, 2005; Antisari et al., 2013). Consistently with our results, in previous research (GarciaFraile et al., 2012) beneficial microorganisms application resulted in the increase of pepper fruit number and weight compared to the non-inoculated control.

\section{Antioxidant content and activity}

From the analysis of variance relevant to the antioxidants content in pepper fruits (Table 2), the significant effects of cultivar and farming system arose; the year of research did not affect these variables and therefore the relevant data are not reported. Notably, higher values of carotenoids and ascorbic acid were recorded in 'Yolo
Wonder' red fruits compared to 'Brillant' yellow berries, whereas no significant differences were detected with regard to $\alpha$-tocopherol, polyphenols and flavonoids. In previous research (Simonne et al., 1997) ascorbic acid did not significantly differ between pepper red and yellow fruits, but, consistently with our results, higher carotenoids concentration was detected in red berries. Tundis et al. (2013) also reported higher levels of carotenoids in pepper red fruits than in yellow berries and, in addition, no polyphenols difference; moreover, unlike our findings, these authors detected higher flavonoids, in one of the two red fruit cultivars tested, and higher tocopherol accumulation in yellow berry variety.

As for farming system, OMF resulted in the highest values of all the antioxidants, followed by CMF, whereas the Organic control plant fruits showed the lowest contents.

Among the antioxidants examined, only the polyphenols concentration was significantly affected by the interaction between year of research and farming system (Fig. 1), which resulted in both years in the highest values of this variable under $\mathrm{CMF}$, followed by OMF, and the lowest in both Conventional (C) and Organic (O) control; moreover, CMF led to higher polyphenols amount in 2015 whereas OMF showed a better effect in the second year.

The antioxidant activities assessed with both the ABTS and the DPPH method did not significantly differ between the cultivars examined (on average, 166 and $156 \mu \mathrm{mol} \cdot 100$ $\mathrm{g}^{-1}$ d.w. upon ABTS and DPPH assay respectively). Unlike our results, Tundis et al. (2013) detected a higher antioxidant activity in pepper yellow fruits than in red ones, using the DPPH method.

The antioxidant activity assessed with the ABTS method was significantly affected by the interaction between year of research and farming system (Fig. 2). Indeed, OMF best affected this variable in both years, whereas Conventional control (C) showed the worst effect; moreover, CMF resulted in higher fruit antioxidant activity in 2015 than in 2016, while the other treatments did not differ between the two research years.

The antioxidant activity assessed with the DPPH method showed similar trends as with ABTS method, both in 2015 and in 2016 (Fig. 3); in addition, this parameter was better affected in 2016 than in 2015 by Conventional control (C), whereas no differences between the two research years were recorded under the other treatments.

Table 1. Yield and growth of pepper as affected by year of research, cultivar and farming system

\begin{tabular}{|c|c|c|c|c|c|}
\hline Treatment & Early yield $\left(\mathrm{t} \cdot \mathrm{ha}^{-1}\right)$ & Total yield $\left(\mathrm{t} \cdot \mathrm{ha}^{-1}\right)$ & No. fruits per plant & Mean fruit weight $(\mathrm{g})$ & $\operatorname{LAI}\left(\mathrm{m}^{2} \cdot \mathrm{m}^{-2}\right)$ \\
\hline \multicolumn{6}{|c|}{ Year } \\
\hline 2015 & 15.7 & 53.3 & 20.2 & 97.8 & 3.0 \\
\hline 2016 & 22.2 & 69.7 & 20.4 & 107.0 & 3.3 \\
\hline Significance & * & * & n.s. & * & * \\
\hline \multicolumn{6}{|c|}{ Cultivar } \\
\hline 'Brillant' & 19.3 & 62.1 & 21.7 & 98.0 & 3.2 \\
\hline 'Yolo Wonder' & 18.6 & 60.9 & 18.9 & 106.8 & 3.1 \\
\hline Significance & n.s. & n.s. & * & * & n.s. \\
\hline \multicolumn{6}{|c|}{ Fertilization } \\
\hline $\mathrm{C}$ & $17.2 \mathrm{c}$ & $57.9 \mathrm{c}$ & $20.1 b$ & $96.5 b$ & $2.8 \mathrm{~b}$ \\
\hline CMF & $24.7 \mathrm{a}$ & $75.5 \mathrm{a}$ & $24.5 \mathrm{a}$ & $109.1 \mathrm{a}$ & $3.7 \mathrm{a}$ \\
\hline $\mathrm{O}$ & $14.3 \mathrm{~d}$ & $49.1 \mathrm{~d}$ & $17.9 \mathrm{c}$ & $91.6 \mathrm{c}$ & $2.3 \mathrm{c}$ \\
\hline OMF & $19.4 b$ & $63.4 b$ & $18.7 \mathrm{c}$ & $112.4 a$ & $3.6 a$ \\
\hline
\end{tabular}

n.s. No statistically significant
to the Duncan test at $\mathrm{p} \leq 0.05$. 
462

Table 2. Antioxidants content in pepper fruits $(\mathrm{mg})$

\begin{tabular}{|c|c|c|c|c|c|c|}
\hline Treatment & $\beta$-criptoxantine & $\alpha$-carotene & $\beta$-carotene & Ascorbic acid & $\alpha$-tocopherol & Flavonoids \\
\hline \multicolumn{7}{|c|}{ Cultivar } \\
\hline 'Brillant' & 3.7 & 17.0 & 49.4 & 1874.1 & 277.7 & 88.3 \\
\hline 'Yolo Wonder' & 36.9 & 60.7 & 201.6 & 2616.6 & 290.2 & 92.5 \\
\hline Significance & * & * & * & * & n.s. & n.s. \\
\hline \multicolumn{7}{|c|}{ Fertilization } \\
\hline $\mathrm{C}$ & $19.4 \mathrm{c}$ & $37.2 \mathrm{c}$ & $119.3 \mathrm{c}$ & $2135.1 \mathrm{c}$ & $271.4 \mathrm{c}$ & $80.0 \mathrm{c}$ \\
\hline $\mathrm{CMF}$ & $22.7 b$ & $41.7 \mathrm{~b}$ & $129.6 \mathrm{~b}$ & $2492.9 \mathrm{~b}$ & $297.3 \mathrm{~b}$ & $103.7 \mathrm{~b}$ \\
\hline $\mathrm{O}$ & $14.6 \mathrm{~d}$ & $31.7 \mathrm{~d}$ & $110.2 \mathrm{~d}$ & $1608.9 \mathrm{~d}$ & $248.0 \mathrm{~d}$ & $65.2 \mathrm{~d}$ \\
\hline OMF & $24.6 a$ & $44.7 \mathrm{a}$ & $142.7 \mathrm{a}$ & $2744.6 a$ & $318.9 a$ & $112.6 \mathrm{a}$ \\
\hline
\end{tabular}

n.s. not significant; ${ }^{*}$ significant difference at $\mathrm{p} \leq 0.05$. Within each column, means followed by different letters are significantly different according to the Duncan test at $\mathrm{p} \leq 0.05$. Data are per $100 \mathrm{~g} \mathrm{dw}$ of fruit tissue homogenate.

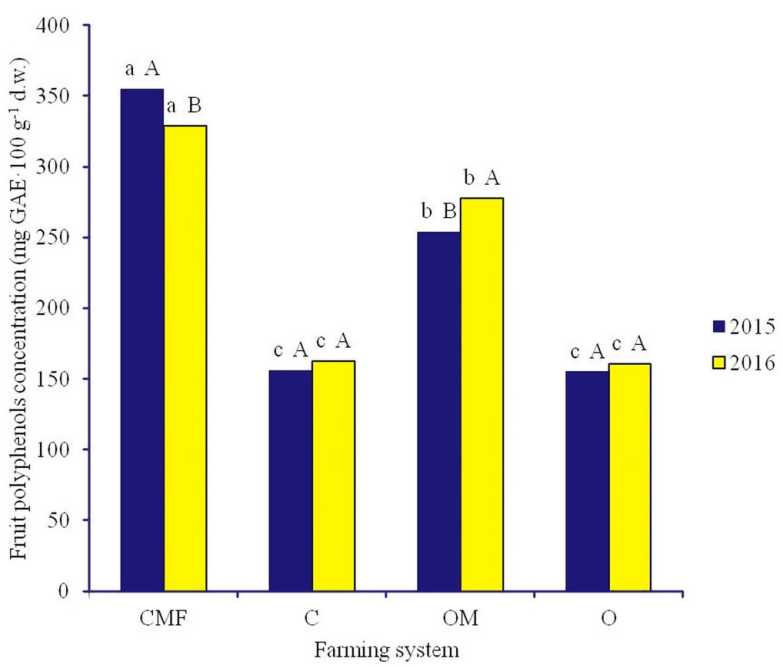

Fig. 1. Interaction between year of research and farming system on pepper fruit polyphenol concentration. Lower case letters refer to the comparison between farming systems values, whereas capital letters refer to the comparison between years of research values

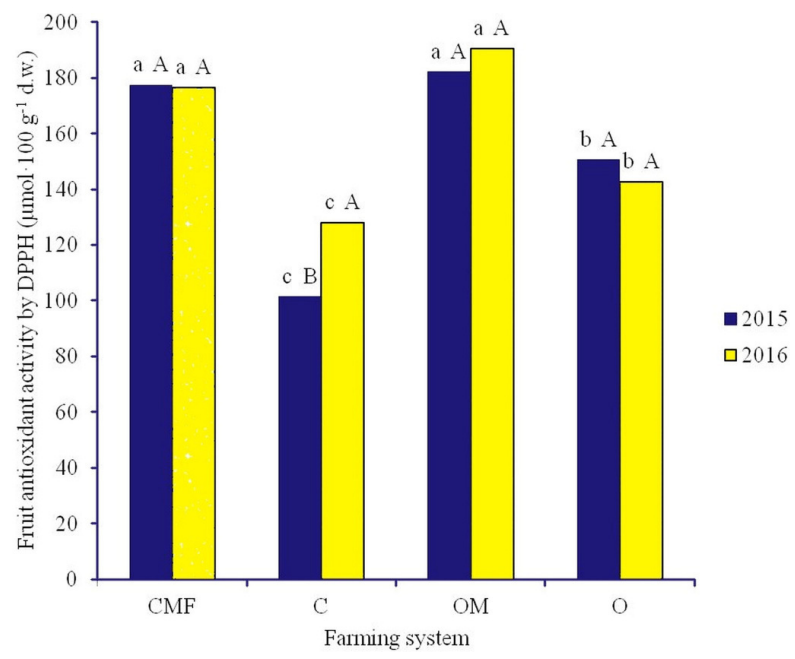

Fig. 3. Interaction between year and farming system on pepper fruit antioxidant activity ( $\mathrm{DPPH}^{+}$method). Lower case letters refer to the comparison between farming systems values, whereas capital letters refer to the comparison between years of research values

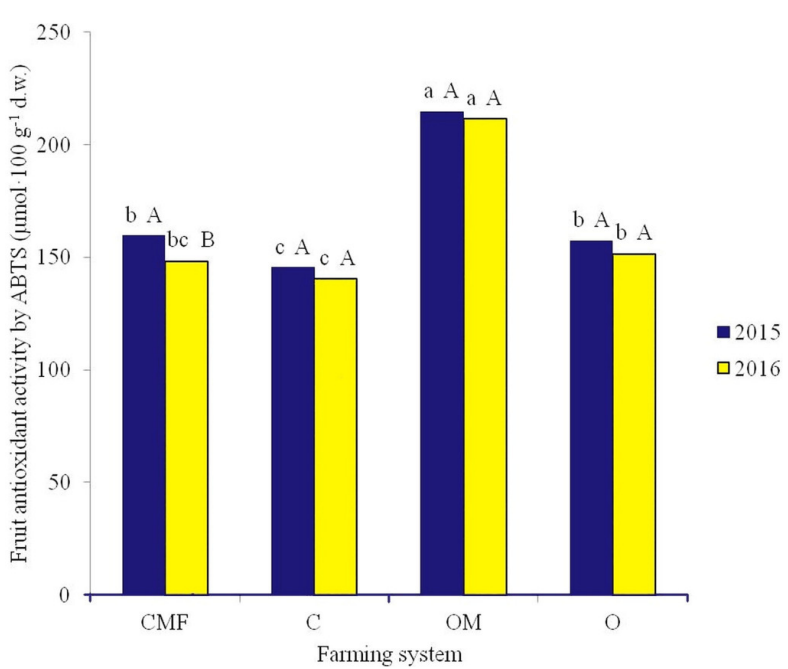

Fig. 2. Interaction between year of research and farming system on pepper fruit antioxidant activity $\left(\mathrm{ABTS}^{+}\right.$method). Lower case letters refer to the comparison between farming systems values, whereas capital letters refer to the comparison between years of research values

Unlike our findings, Flores et al. (2009) did not detect any significant differences in antioxidant content as well as in hydrophilic activity of pepper red berries between conventional and organic management.

Consistently with our results, in previous research carried out on tomato (Ochoa-Velasco et al., 2016) a beneficial effect of Bacillus licheniformis application was recorded on fruit ascorbic acid, flavonoids and polyphenols content as well as on antioxidant activity, but the microorganism action was enhanced by the increased nitrogen availability. The latter phenomenon was also confirmed in our research, in which both CMF and OMF resulted in higher fruit polyphenols concentration than Conventional and Organic controls which lacked with beneficial microorganisms providing the plants with more readily absorbable nitrogen. Conversely, according to other authors reports (Le Bot et al., 2009) nitrate concentration rise in nutrient solution causes a detrimental effect on plant phenolics synthesis, as the secondary metabolites elaboration is associated to defense mechanism. 


\section{Conclusions}

From the research carried out with the aim to assess the effects of cultivar and farming system on yield and fruit quality of tunnels grown sweet pepper, the following remarks can be drawn. Although no varietal yield differences arose, the red berry cultivar ('Yolo Wonder') showed a higher fruit concentration of carotenoids and vitamin $\mathrm{C}$ than the yellow fruit one ('Brillant'). Moreover, the CMF system resulted in the highest early and total fruit production, due to the higher nutrient use efficiency compared to both the $\mathrm{C}$ and $\mathrm{O}$ management based on traditional fertilization pattern. Interestingly, the beneficial microorganism application within the $\mathrm{O}$ system led to better yield performances than the $\mathrm{C}$ system, in spite of halved nutrient inputs, and to the best fruit quality, in terms of antioxidant concentration and activity. Taking into account the increasing consumer demand for healthy produce and the current policies targeted to environmentally sustainable crop systems, the $\mathrm{O}$ system including the beneficial microorganism support represents a coherent alternative to $\mathrm{C}$ farming practices based on chemical inputs.

\section{Acknowledgements}

The authors wish to thank Mr. Antonio Cuciniello for his help with laboratory analyses cooperation.

\section{References}

Antisari LV, Falsone G, Carbone S, Vianello G (2013). Short-term effects of forest recoveryon soil carbon and nutrient availability in an experimental chestnut stand. Biology and Fertility ofSoils 49:165-173.

Authority EFS (2008). Nitrate in vegetables: scientific opinion of the panel on contaminants in the food chain. The EFSA Journal 689:1-79.

Berova M, Karanatsidis G (2009). Physiological response and yield of pepper plants (Capsicum annum L.) to organic fertilization. Journal of Central European Agriculture 9(4):715-722.

Butnariu M (2014). Detection of the polyphenolic components in Ribes nigrum L. Annals of Agriculture and Environmental Medicine 21: 1114

Chen L, Kang YH (2013). Anti-inflammatory and antioxidant activities of red pepper (Capsicum annuum L.) stalk extracts: comparison of pericarp and placenta extracts. Journal of Functional Foods 5:1724-1731.

Conti S, Villari G, Faugno S, Mulchionna G, Somma S, Caruso G (2014). Effect of organic vs. conventional farming system on yield and quality of strawberry grown as an annual or biennal crop in southern Italy. Scientia Horticulture 180:63-71.

Costa AGV, Garcia-Diaz DF, Jimenez P, Silva PI (2013). Bioactive compounds and health benefits of exotic tropical red-black berries. Journal of Functional Foods 5:539-549.

Deepa N, Charanjit K, Binoy G, Balraj S, Kapoor HC (2007). Antioxidant constituents in some sweet pepper (Capsicum annum L.) genotypes during maturity.LWT - Food Science and Technology 40:121-129.

Del Amor FM, Serrano-Martınez A, Fortea MI, Legua P, Nuez-Delicado E
(2008). The effect of plant-associative bacteria (Azospirillum and Pantoea) on the fruit quality of sweet pepper under limited nitrogen supply. Scientia Horticulture 117:191-196.

FAOSTAT (2014): Food and Agriculture Organization of the United Nations. Statistics Division. Retrieved on March 18, 2015 from http://faostat.fao.org

Flores P, Hellín P, Lacasa A, López A, Fenoll J (2009). Pepper antioxidant composition as affected by organic, low-input and soilless cultivation. Journal of Science and Food Agriculture 89:2267-2274.

Graham MH, Haynes RJ (2005). Organic matter accumulation and fertilizer-induced acidification interact to affect soil microbial and enzyme activity on a long-term sugarcane management experiment. Biology and Fertility ofSoils 41:249-256.

Grajeda-Iglesias C, Salas E, Barouh N, Baréa B, Panya A, Figueroa-Espinoza MC (2016). Antioxidant activity of protocatechuates evaluated by DPPH, ORAC, and CAT methods. Food Chemistry 194:749-757.

Khah EM, Passam HC (1992). Flowering, fruit set and development of the fruit and seed of sweet pepper (Capsicum annuum L.) cultivated under conditions of high ambient temperature. Journal of Horticulture and Science 67:251-258.

Krüger M, Krüger C, Wlaker C, Stockinger H, Schüler A (2012). Phylogenetic reference data of systematics and phylotaxonomy of arbuscular mycorrhizal fungi from phylum to species level. New Phytology 193:970-984.

Larrosa APQ, Cadaval TRS, Pinto LAA (2015). Influence of drying methods on the characteristics of a vegetable paste formulated by linear programming maximizing antioxidant activity. LWT - Food Science and Technology 60(1):178-185.

Le Bot J, Bernard C, Robin C, Bourgaud F, Adamowicz S (2009). The 'trade-off' between synthesis of primary and secondary compounds in young tomato leaves is altered by nitrate nutrition: experimental evidence and model consistency. Journal of Experimental Botany 60(15):4301-4314.

Loizzo M, Pugliese A, Bonesi M, Menichini F, Tundis R(2015). Evaluation of chemical profile and antioxidant activity of twenty cultivars from Capsicum annuum, Capsicum baccatum, Capsicum chacoense and Capsicum chinense: a comparison between fresh and processed peppers. LWT-Food Science and Technology 64:623-631.

López A, Fenoll J, Hellín P, Flores P (2013). Physical characteristics and mineral composition of two pepper cultivars under organic, conventional and soilless cultivation. Scientia Horticulture 150:259266.

Lopez A, Fenoll J, Hellin P, Flores P (2014). Cultivation approach for comparing the nutritional quality of two pepper cultivars grown under different agricultural regime. LWT - Food Science and Technology 58: 299-305.

Luning PA, van der Vuurst de Vries R, Yuksel D, Ebbenhorst-Seller T, Wichers HJ, Roozen JP (1994). Combined instrumental and sensory evaluation of flavor of fresh bell peppers (Capsicum annuum) harvested at three maturation stages. Journal of Agriculture and Food Chemistry 42:2855-2861.

Maynard AA (1994). Sustained vegetable production for three years using composted animal manures. Compost Science and Utilization 2(1):8896. 
464

Nadeem SM, Ahmad M,Zahir ZA, Javaid A, AshrafM(2014). The role of mycorrhizae and plant growth promoting rhizobacteria (PGPR) in improving crop productivity under stressful environments. Biotechnology Advance 32(2):429-448.

Ochoa-Velasco CE, Valadez-Blanco R, Salas-Coronado R, Sustaita-Rivera F, Hernández-Carlos B, García-Ortega S, Santos-Sánchez NF (2016). Effects of nitrogen fertilization and Bacillus licheniformis biofertilizer addition on the antioxidants compounds and antioxidant activity of greenhouse cultivated tomato fruits (Solanum lycopersicum L. var. Sheva). Scientia Horticulture 201:338-345.

Ortas I,Nebahat S, Akpinar C, Halit Y (2011). Screening mycorrhizaspecies for plant growth, $\mathrm{P}$ and $\mathrm{Zn}$ uptake in pepper seedling grown under greenhouse conditions. Scientia Horticulture 128:92-98.

Owen D, Williams AP, Griffith GW, Withers PJA (2015). Use of commercial bio-inoculants to increase agricultural production through improved phosphorus acquisition. Applied Soil Ecology 86:41-54.

Re R, Pellegrini N, Proteggente A, Pannala A, Yang M, Rice-Evans C (1999) Antioxidant activity applying an improved ABTS radical cation decolorization assay. Free Radical Biology and Medicine 26:1231-1237.

Rouphael Y, Franken Ph, Schneider C, Schwarz D, Giovannetti M, Agnolucci M, De Pascale S, Bonini P, Colla G (2015). Arbuscular mycorrhizal fungi act as biostimulants in horticultural crops. Scientia Horticulture 196:91-108.

Serpeloni JM, Leal Specian AF, Ribeiro DL, Tuttis K, Vilegas W, MartínezLópez W, ... Varanda EA (2015). Antimutagenicity and induction of antioxidant defense by flavonoid rich extract of Myrcia bella Cambess, in normal and tumor gastric cells. Journal of Ethnopharmacology 176:345355.
Shahidi F, Ambigaipalan P (2015). Phenolics and polyphenolics in foods, beverages and spices: antioxidant activity and health effects - A review. Journal of Functional Foods Part B 18:820-897.

Shaked R, Rosenfeld K, Pressman E (2004) The effects of low night temperatures on carbohydrates metabolism in developing pollen grains of pepper in relation to their number and functioning. Scientia Horticulture 102:29-36.

Simonne AH, Simonne EH, Eitenmiller RR, Milles HA, Green NR (1997). Ascorbic acid and provitamin A contents in unusually coloured bell peppers (Capsicum annuum L.). Journal of Food Composition and Analysis 10(4):299-311.

Smith SE, Read DJ (2008). Mycorrhizal Symbiosis, 3rd ed. AcademicPress, London.

Sreeramulu D, Raghunath M (2010). Antioxidant activity and phenolic content of roots, tubers and vegetables commonly consumed in India. Food Research International 43:1017-1020.

Stoleru V, Munteanu N, Sellitto VM (2014). New approach of organic vegetable systems. Aracne Editrice, chapter 4, Rome.

Thanopoulos C, Akoumianakis KA, Passam HC (2013). The effect of season on the growth and maturation of bell peppers. International Journal of Plant Production 7:279-294.

Tundis R, Menichini F, Bonesi M, Conforti F, Statti G, Menichini F, Loizzo $M$ (2013). Antioxidant and hypoglycaemic activities and their relationship to phytochemicals in Capsicum annuum cultivars during fruit development.LWT - Food Science and Technology 53:370-377.

Zhuang Y, Chen L, Sun L, Cao J (2012). Bioactive characteristics and antioxidant activities of nine peppers. Journal of Functional Foods 4:331-338 